\title{
Density Functional Theory of Mild Steel Corrosion in Acidic Media Using Dyes as Inhibitor: Adsorption onto $\mathrm{Fe}(110)$ from Gas Phase
}

\author{
R. S. Oguike, A. M. Kolo, A. M. Shibdawa, and H. A. Gyenna \\ Material Science Research Laboratory, Department of Chemistry, Abubakar Tafawa Balewa University Bauchi, \\ PMB 0248, Bauchi, Nigeria
}

Correspondence should be addressed to R. S. Oguike; oguike.raphael@yahoo.com

Received 15 January 2013; Accepted 13 March 2013

Academic Editors: T. Bligaard, J. G. Han, and B.-T. Liu

Copyright (C) 2013 R. S. Oguike et al. This is an open access article distributed under the Creative Commons Attribution License, which permits unrestricted use, distribution, and reproduction in any medium, provided the original work is properly cited.

Quantum chemical calculations based on density functional theory (DFT) methods were performed on indigo blue (IB), methylene blue (MB), and crystal violet (CV) molecules as inhibitors for iron corrosion in acid media. DFT calculations were performed on the molecular structures to describe electronic parameters which are associated with inhibition efficiency such as the $E_{\mathrm{Homo}}$ values $-4.981 \mathrm{eV},-4.518 \mathrm{eV}$, and $-3.872 \mathrm{eV}$ which increased in the order $\mathrm{IB}>\mathrm{MB}>\mathrm{CV}$ while $E_{\mathrm{LUMO}}$ values were $-3.73 \mathrm{eV},-3.63 \mathrm{eV}$, and $-2.87 \mathrm{eV}$ for $\mathrm{IB}, \mathrm{MB}$, and $\mathrm{CV}$, respectively. Quench molecular dynamics simulations performed at metal/vacuum interface were applied to find the equilibrium adsorption configurations and calculate the minima interaction energy between inhibitor molecules and iron surface $\mathrm{Fe}(110)$. The theoretical order of inhibition efficiency of these dye molecules had a linear relationship with experimentally observed inhibition efficiency on iron corrosion in acid media. The electronic structures as well as reactivity elucidate parameters which could be practical in designing novel high-efficiency, cheap, and eco-friendly inhibitors by quantitative structure-activity relationship (QSAR) method.

\section{Introduction}

A dye is a coloured substance that has an affinity to the substrate to which it is being applied. Dyes are obtained from animal, vegetable, or mineral origin and appear to be coloured because they absorb some wavelengths of light. Dyes are in our ancient science and effects of dyes are known in the medical industry, textile industry, and cellulose industries and in recent times as corrosion inhibitors of metals both in acidic and alkaline aggressive environments, as redox indicator in analytical chemistry, photosensitizer used to create singlet oxygen when exposed to both oxygen and light, to examine RNA or DNA gel electrophoresis, and also in a number of different staining procedures such as Wright's stain and Jenner's stain [1-5]. The corrosion inhibition characteristics of dye are attributed to adsorption of the dye molecule on the metal surface, hence reducing the surface area susceptible to attacks by the corrosive media. This might be by algebraic blocking of active sites on the metal surface or by polarizing the individual metal atoms to which they are adsorbed thereby influencing the intrinsic reactivity of the metal [6]. Many researchers report that the inhibition effect mainly depends on some physicochemical and electronic properties of the organic inhibitor which relate to its functional groups, steric effects, electronic density of donor atoms, orbital character of donating electrons, and so on. The concept of assessing the efficiency of a corrosion inhibitor with the help of computational chemistry is to search for compounds with desired properties using chemical intuition and experience into a mathematically quantified (development of efficient algorithms) and computerized form [7-15].

Quantum chemical methods have already proven to be very useful in determining the molecular structure as well as elucidating the electronic structure and reactivity which could be practical in designing novel high-efficiency inhibitors by quantitative structure-activity relationship (QSAR) method [16-19]. These DFT-based quantum-chemical computational simulations of suitable models have made this prevailing tool increasingly available to corrosion scientists for theoretical investigation of corrosion inhibition 
mechanism. Such computations have been widely used to analyze the molecular electronic structures of a wide range of adsorption-type inhibitors using a number of quantum chemical descriptors, which has given important physical insights on corrosion inhibition mechanisms [20-25]. Accordingly, inhibition efficiency is correlated to the molecular and structural parameters that can be obtained through theoretical calculations such as chemical selectivity, reactivity, and charge distribution. Other quantum chemical results are the frontier molecular orbital; HOMO (higher occupied molecular orbital) energy, the LUMO (lower unoccupied molecular orbital) energy, chemical potential $(\mu)$ and hardness $(\eta)$, electronegativity $(\chi)$, and electron transfer number $(\Delta N)$ among others.

The main objective of corrosion inhibitor computational research is to gain insight into the mechanisms by which inhibitors added to a fluid aggressive environment retard the metal-corrodent interaction. Indeed, the effectiveness of the overall process is a function of the metal surface, corrosive media, molecular and electronic structure, and concentration of the inhibitor, as well as temperature and other environmental considerations [7-15, 25]. Several organic compounds have been studied by computational simulations but theoretical reports on dyes are rather scarce. In this present study, we are reporting theoretical study on electronic and molecular structures of 3,7-bis(Dimethylamino)-phenothiazin-5-ium chloride (Methylene Blue dye (MB)), Tris(4-(dimethylamino)phenyl) methylium chloride (Crystal Violet dye (CV)), and 2,2'-Bis(2,3-dihydro-3-oxoindolyliden) (Indigo Blue dye (IB)) and to determine relationship between molecular structure of the compounds and inhibition efficiency on mild steel from gas phase. This was done by discussing the quantum chemical and structural parameters, local reactivity indices such as the Fukui function, and the adsorption characteristics of the three dye molecules on the iron surface using quench molecular dynamics simulations. Figure 1 shows the Lewis structures of the investigated dyes and their optimized structures.

\section{Computations}

Quantum chemical methods and molecular modeling techniques enable the definition of a large number of molecular quantities characterizing the reactivity, shape, and binding properties of a complete molecule. However, molecular mechanics simulation is relatively coarser than quantum chemical calculation, because the former only carries out total atom calculations while the latter executes total electron calculations. With molecular mechanics methods, the adsorption state of inhibitor monolayer formed on metal surface can be investigated via analysis of interfacial configuration, interaction between monolayer and metal surface, cohesive energy of monolayer, and so forth [26-28]. The geometry optimization process was carried out for the studied dyes; $\mathrm{MB}, \mathrm{CV}, \mathrm{IB}$, and the Fe surface using an iterative process, in which the atomic coordinates are adjusted until the total energy of the structure corresponds to a local minimum in the potential energy surface (without imaginary frequency). These were modeled by Materials Studio; MS Modeling version 4.0 [29], high-quality quantum mechanics computer program (available from Accelrys, San Diego, CA, USA). The electronic structures of inhibitor molecules and the Fe surface were modeled by means of the DFT electronic structure program DMol3 using a Mulliken population analysis as well as a Hirshfeld numerical integration procedure. Electronic parameters for the simulation include restricted spin polarization using the DNP basis set and local potential Perdew and Wang (PWC) exchange-correlation potential functional [25]. To clearly account for all electrons and introduce some relativistic effects into the core, we used all-electron relativistic (AER) as the core treatment. $2 \times 2 \times 1$ mesh parameters was set as $k$ point with custom grid for the metal surface and density mixing charge was set to default using Direct Inversion in an Iterative Subspace (DIIS) with $0.14 \mathrm{eV}$ thermal smearing applied to the orbital occupation to speed up convergence alongside convergence tolerance maximum force at $0.11 \mathrm{eV} / \AA$. Molecular dynamics (MD) simulation of the interaction between single inhibitor molecules and the Fe surface was performed using Forcite quench molecular dynamics [25] in the MS Modeling 4.0 software to sample many different lowenergy configurations and identify the low-energy minima. The Fe crystal was relaxed via minimizing its energy by geometry optimization and the surface cleaved along the (110) plane. The symmetry was increased and its periodicity changed by constructing a supercell $12 \times 10$ with a vacuum slab of $20 \AA$ height, modeled as a representative part of the interface, devoid of arbitrary boundary effects. Calculations were carried out, using the COMPASS (condensed-phase optimized molecular potentials for atomistic simulation studies) force field and the Smart algorithm, in a simulation box $29.79 \AA \times 24.79 \AA \times 24.05 \AA$ with periodic boundary conditions; temperature was fixed at $303 \mathrm{~K}$, with NVE (microcanonical) ensemble, with a time step of $0.1 \mathrm{fs}$ and simulation time of $0.5 \mathrm{ps}$. The system was quenched every 250 steps with convergence tolerance energy at $1.0^{-3} \mathrm{kcal} / \mathrm{mol}$.

The local reactivity of the molecules was analyzed through an evaluation of the Fukui function as a measurement of the chemical reactivity; indicative of the reactive regions, that is, the nucleophilic and electrophilic behaviour of the molecule. Calculations are based on the finite difference approximations and partitioning of the electron density $\rho(r)$ between atoms in a molecular system [30],

$$
\begin{array}{ll}
f^{+}=g_{k}(N+1)-g_{k}(N) & \text { (nucleophilic attack), } \\
f^{-}=g_{k}(N)-g_{k}(N-1) & \text { (electrophilic attack). }
\end{array}
$$

Herein, $g_{k}$ is the gross charge of atom $k$ in the molecule and $N$ is the number of electrons. The condensed Fukui function is local reactivity descriptor and can be used only for comparing reactive atomic centres within the same molecule. The binding energy $\left(E_{\text {Bind }}\right)$ of iron surface with inhibitor molecules was calculated according to the following equation [11]:

$$
E_{\mathrm{Bind}}=E_{\mathrm{Fe} \text {-inhibitor }}-\left(E_{\mathrm{Fe}}+E_{\mathrm{Inh}}\right) .
$$

Herein, $E_{\mathrm{Fe}-\text { inh }}$ is the total energy of the Fe crystal together with the adsorbed inhibitor molecule. $\left(E_{\mathrm{Fe}}\right.$ and $\left.E_{\mathrm{Inh}}\right)$ is the total energy of the iron crystal and free inhibitor molecule, 
<smiles>CN(C)c1ccc2nc3ccc(=[N+](C)C)cc-3sc2c1</smiles><smiles>CN(C)c1ccc(C(=C2C=CC(=[N+](C)C)C=C2)c2ccc(N(C)C)cc2)cc1</smiles><smiles>O=C1C(=C2Nc3c([nH]c4ccccc34)C2=O)c2ccccc21</smiles>

(a)
Methylene blue dye

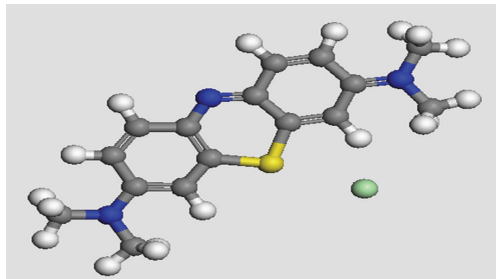

Crystal violet dye

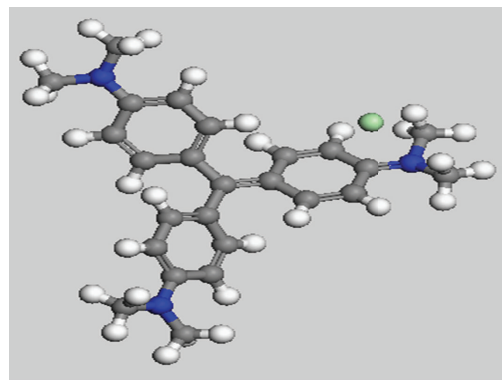

Indigo blue dye

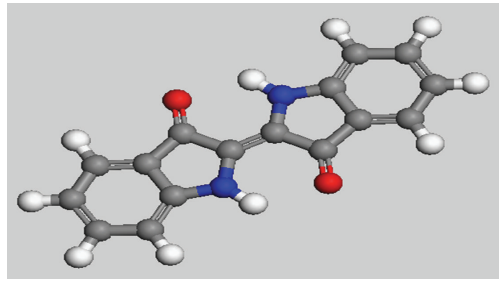

(c)

Figure 1: (a) Lewis structures of the investigated dyes, (b) names, (c) geometry-optimized structures [C, gray; $\mathrm{H}$, white; N, blue; O, red; Cl, green].

respectively. The number of electrons transferred $(\Delta N)$ from the inhibitor molecule to the metallic atom was also calculated using the following equation [30]:

$$
\Delta N=\frac{\chi_{\mathrm{Fe}}-\chi_{\mathrm{Inh}}}{2\left(\eta_{\mathrm{Fe}}+\eta_{\mathrm{Inh}}\right)}
$$

Herein, $\chi_{\mathrm{Fe}}$ and $\chi_{\mathrm{Inh}}$ represent the absolute electronegativity of iron and the inhibitor molecule, respectively; $\eta_{\mathrm{Fe}}$ and $\eta_{\mathrm{Inh}}$ represent the absolute hardness of iron and the inhibitor molecule.

\section{Results and Discussion}

3.1. Molecular Reactivity. The molecular reactivity was investigated via analysis of the frontier molecular orbital and Fukui functions. The highest occupied molecular orbital (HOMO) and the lowest unoccupied molecular orbital (LUMO) of the dye molecules are showed in Figure 2 while the Fukui indices and electron density are shown in Figure 6. It could be seen that the HOMO orbitals of IB dye molecule are generally delocalized around the double bond and heteroatoms. This kind of orbital distribution could be ascribed to the high electron density around the centre of the molecule due to the $\mathrm{p}-\pi$ conjugation effect. As a result, the centre of the molecule would be preferentially adsorbed onto metal surface as active sites. During adsorption, the inhibitor molecule could donate electrons to form coordinate bond with unoccupied d-orbitals of metal accept electrons from d-orbital of metal, and form back-donating bonds as well. High $E_{\text {HOMO }}$ facilitates adsorption (inhibition) by influencing the transport process through the adsorbed layer, whereas lowlying LUMO induces a backdonation of charge from the metal to the molecule [31]. We found that CV had its HOMO orbital chiefly on the $\mathrm{Cl} 29$ and $\mathrm{C} 9=\mathrm{C} 10$ double bond had a little effect as also confirmed in Mulliken atomic charges (Table 1). Analyzing the HOMO orbital of MB, we observed it to be predominant at $\mathrm{Cl} 21$ and S10-C11 had contributions to the electron density. These could possibly mean a coordinate bond during adsorption to protect anodic areas and reduce the inherent reactivity of the metal at the sites where they are attached. It is considered that $\mathrm{MB}$ and $\mathrm{CV}$ are preferably adsorbed on the iron surface by electron acceptance, that is, chemisorptions by backdonation, rather than by donation of p-electrons to the metal. We examined these HOMO orbitals and found that susceptibility of the molecules towards attack by electrophiles and their tenacity to donate electrons are in the following order: $\mathrm{IB}>\mathrm{MB}>\mathrm{CV}$ with $E_{\text {Hомо values }}$ $-4.981 \mathrm{eV},-4.518 \mathrm{eV}$, and $-3.872 \mathrm{eV}$, respectively. Figure 3 shows a linear relationship between the HOMO energy levels and the experimental corrosion inhibition efficiency of the dyes as iron corrosion inhibitor.

Similarly, the LUMO orbital of IB dye molecule was principally found around aldehyde function and the amines; 
HOMO
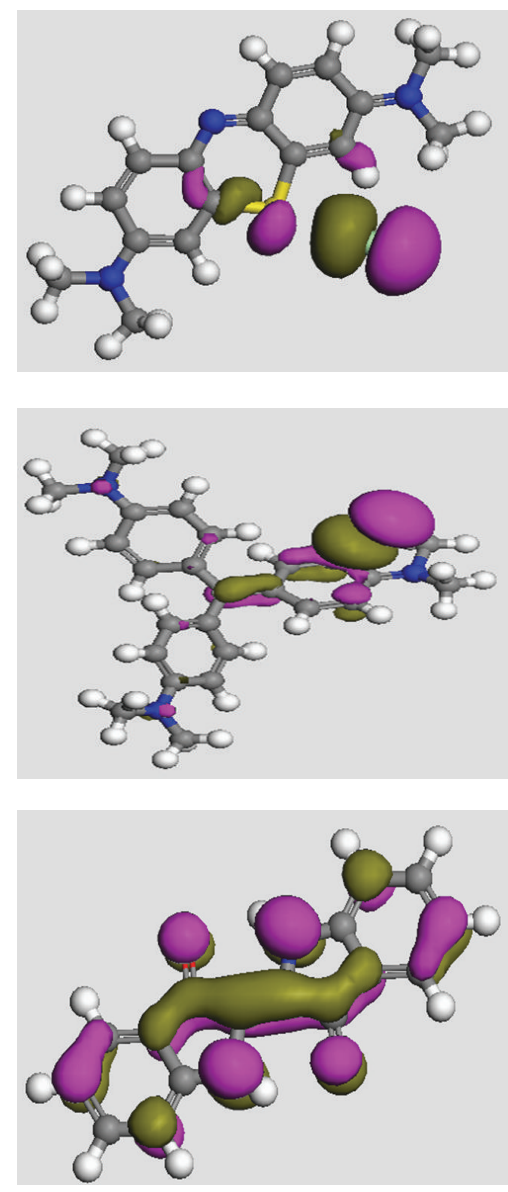

(a)
LUMO

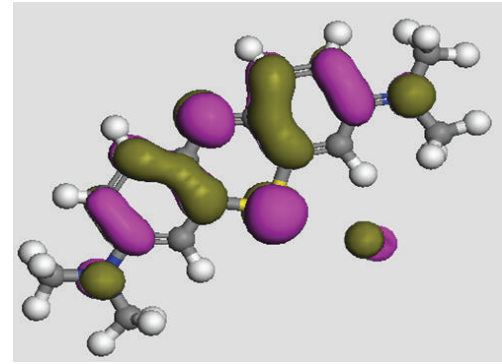

Methylene blue

Crystal violet

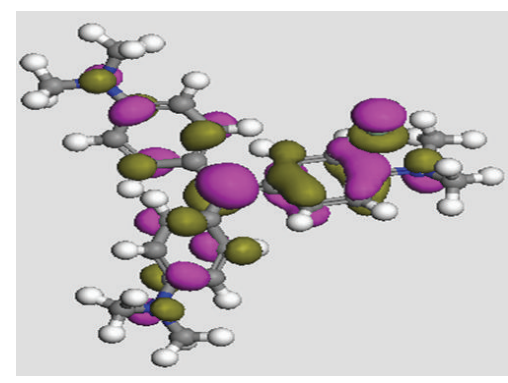

Indigo blue

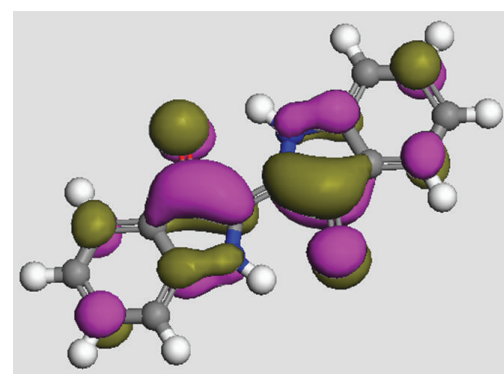

(b)

FIgURE 2: The frontier molecular orbital density distributions of the three dyes: HOMO (a); LUMO (b).

TABLE 1: Condensed Fukui indices (Mulliken analyses) of IB, MB, and $\mathrm{CV}$ in gas phase.

\begin{tabular}{cccc}
\hline & $f^{-}$ & $f^{+}$ & Mulliken atomic charges \\
\hline \multirow{4}{*}{ IB } & $\mathrm{N}(7) 0.046$ & $\mathrm{C}(9) 0.050$ & $\mathrm{~N}(7)-0.415$ \\
& $\mathrm{O}(19) 0.072$ & $\mathrm{O}(19) 0.087$ & $\mathrm{~N}(14)-0.416$ \\
& $\mathrm{O}(20) 0.071$ & $\mathrm{O}(20) 0.087$ & $\mathrm{O}(19)-0.475$ \\
& & & $\mathrm{O}(20)-0.475$ \\
\hline \multirow{4}{*}{$\mathrm{MB}$} & $\mathrm{N}(7) 0.061$ & $\mathrm{~N}(7) 0.066$ & $\mathrm{~N}(7)-0.295$ \\
& $\mathrm{~S}(10) 0.056$ & $\mathrm{~S}(10) 0.066$ & $\mathrm{~S}(10) 0.009$ \\
& $\mathrm{Cl}(21) 0.238$ & $\mathrm{Cl}(21) 0.195$ & $\mathrm{~N}(15)-0.339$ \\
& & & $\mathrm{~N}(16)-0.332$ \\
& & & $\mathrm{Cl}(21)-0.583$ \\
$\mathrm{CV}$ & $\mathrm{Cl}(10) 0.054$ & $\mathrm{C}(10) 0.061$ & $\mathrm{C}(10) 0.120$ \\
& & $\mathrm{Cl}(29) 0.149$ & $\mathrm{~N}(7)-0.345$ \\
& & & $\mathrm{~N}(24)-0.346$ \\
\end{tabular}

consequently these are favorite sites for interaction with the metal. It could also be seen in Figure 2 that LUMO orbital of $\mathrm{MB}$ and $\mathrm{CV}$ is delocalized but comparing the net atomic

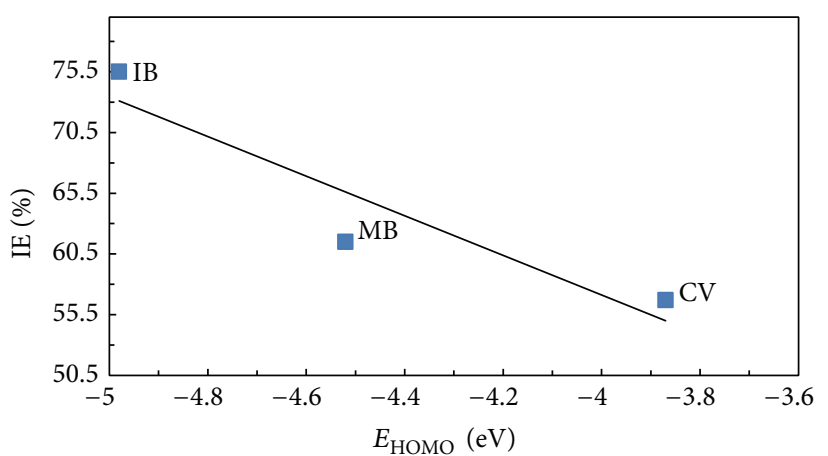

FIGURE 3: Correlation of HOMO energy with percent inhibition efficiency of dye molecules.

charges of their $\mathrm{Cl}$ atom (Table 1), it is found that $\mathrm{MB}$ has a stronger interaction with iron and has a better corrosion inhibition effect on iron than CV. According to the frontier molecular orbital theory, low values of $E_{\text {LUMO }}$ should also indicate a strong tendency of electron-accepting abilities of the molecule and as seen in Figure 3 in the order of 
TABle 2: $E_{\text {HOMO }}, E_{\text {LUMO }}$, chemical potential $(\mu)$, global chemical hardness $(\eta)$, number of electrons transferred $(\Delta N)$, and inhibition efficiency (IE\%) for the three dyes molecules in gas phase.

\begin{tabular}{lcccccc}
\hline & $E_{\text {HOMO }}(\mathrm{eV})$ & $E_{\text {LUMO }}(\mathrm{eV})$ & $\mu(\mathrm{eV})$ & $\Delta N(\mathrm{e})$ & $\eta(\mathrm{eV})$ & $\mathrm{IE}(\%)$ \\
\hline $\mathrm{IB}$ & -4.98 & -3.73 & -4.36 & 2.11 & 0.63 & $75.54^{\mathrm{a}}$ \\
$\mathrm{MB}$ & -4.52 & -3.63 & -4.08 & 3.28 & 0.45 & $61.54^{\mathrm{b}}$ \\
$\mathrm{CV}$ & -3.87 & -2.87 & -3.37 & 3.63 & 0.50 & $56.70^{\mathrm{c}}$ \\
\hline
\end{tabular}

${ }^{\mathrm{a}}[28] ;{ }^{\mathrm{b}}[29] ;{ }^{\mathrm{c}}[32]$.

$\mathrm{IB}>\mathrm{MB}>\mathrm{CV}$ which is in good agreement with inhibition efficiency (IE \%) of the experimental results, see [28, 29, 32].

In addition, inhibition efficiency is closely related to the reactivity of individual molecular orbital contributions to the response of the whole molecular continuum. The fully optimized geometries obtained from the calculations of condense Fukui functions are shown in Figure 6; the results for Fukui function (Table 1) support the trend of the frontier molecular orbital observed for the studied molecules indicating the zones through which the molecule will be adsorbed onto the $\mathrm{Fe}(110)$ surface. The $f^{-}$measures reactivity with respect to electrophilic attack or the characteristic of the molecule to donate electrons, while $f^{+}$measure reactivity which relates to nucleophilic attack or the propensity of the molecule to accept electrons [30]. The highest $f^{-}$for IB is at $\mathrm{O} 19$ and $\mathrm{O} 20$ indicating the zone for transfer of electron as seen in the electron density cloud (Figure 6) while the highest $f^{+}$is associated with the same O19 and O20 showing the ability for a backdonation through the same zone which might result in chemisorption. Moreover, the highest $f^{-}$for $\mathrm{MB}$ and $\mathrm{CV}$ is related to the $\mathrm{Cl}$ atom but the value for $\mathrm{MB}$ is higher than $\mathrm{CV}$ and might readily form adsorptionactive centers, validating that $\mathrm{MB}$ has a higher iron corrosion inhibition efficiency than CV. Calculated results in Table 1 show that the highest $f^{+}$is also at the $\mathrm{Cl}$ atom for $\mathrm{MB}$ and $\mathrm{CV}$, confirming the favorite sites for adsorption.

Furthermore, the global parameters including chemical potential $(\mu)$ and hardness $(\eta)$, electronegativity $(\chi)$, and the number of electrons transferred during the adsorption $(\Delta N)$ were also calculated and the results are shown in Table 2. Since the capability of donating electron of a molecule can be determined by the chemical potential and hardness, the less negative these values are, the higher is the capability of donating electrons [30]. So, from Table 2, it could be seen that the order of electron-donating capability of the dye molecules is $\mathrm{IB}>\mathrm{MB}>\mathrm{CV}$. On the other hand, as for the electronegativity which denotes the electronaccepting capability of a molecule, it could also be deduced from Table 2 that the electron-accepting capability of these molecules follows the similar trend. Generally, the same order of donating capability and accepting electrons of the three inhibitor molecules indicates that the inhibition efficiency would follow the same order of $\mathrm{IB}>\mathrm{MB}>\mathrm{CV}$, which is in accordance with the analysis of frontier molecular orbital. The relationship between corrosion inhibition efficiency and the number of electrons transferred for these three dyes is plotted in Figure 4. As clearly seen in the figure, there is a linearity between inhibition efficiency and number of electrons
TABLE 3: Binding energy, interaction energy, and total energy (minimum) for the molecular dynamic simulations.

\begin{tabular}{lccc}
\hline & $E_{\text {Bind }}(\mathrm{eV})$ & $E_{\text {Interaction }}(\mathrm{eV})$ & Total energy $(\mathrm{kcal} / \mathrm{mol})$ \\
\hline IB & 121.37 & -121.37 & -49.14 \\
MB & 59.62 & -59.62 & -168.3 \\
CV & 39.97 & -39.97 & -86.44 \\
\hline
\end{tabular}

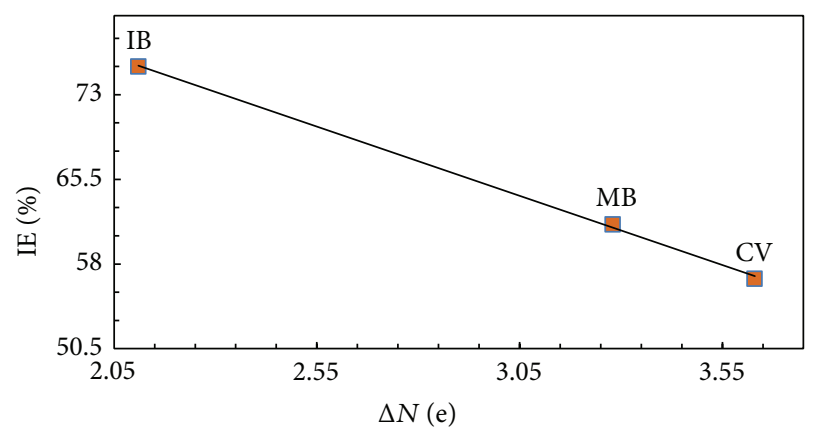

FIGURE 4: Correlation of number of electrons transferred with percent inhibition efficiency of dye molecules.

transferred. In Figure 5, inhibition efficiency is plotted against the chemical potential, showing the inhibition efficiency increased with decrease in the chemical potential energy.

Table 2 provides calculated quantum chemical parameters using (4); number of electrons transferred $(\Delta N)$. Values of $\chi$ and $\eta$ were calculated by using the values of $I\left(-E_{\text {Hомо }}\right)$ and $A\left(-E_{L U M O}\right)$ obtained from quantum chemical calculations. In order to calculate $\Delta N$, a theoretical value for the electronegativity of bulk iron was used $\chi_{\mathrm{Fe}} \approx 7 \mathrm{eV}$, and a global hardness of $\eta_{\mathrm{Fe}} \approx 0$, by assuming that for a metallic bulk $I=A$, because they are softer than the neutral metallic atoms [17]. According to Lukovits, if $\Delta N<3.6$, the inhibition efficiency increased with increasing electron-donating ability at the metal surface [6]. It can be inferred from the calculated results that inhibitors investigated in this study were donors of electrons, and the iron surface was the acceptor.

3.2. Molecular Dynamics. To quantitatively evaluate the most suitable adsorption modes between each molecule and the Fe surface, the adsorption energy $\left(E_{\text {Bind }}\right)$ was calculated using the relationship in (3). In each case the potential energies were calculated by averaging the energies of the five structures of the lowest energy [25]. The obtained values are shown in Table 3; we discovered that IB exhibited the highest binding energy during the simulation process and the order of $E_{\text {Bind }}$ is $\mathrm{IB}>\mathrm{MB}>\mathrm{CV}$ in accordance with experimental inhibition efficiency (IE \%). The high values of the binding energy for the dye molecules could be as a result of dissociative adsorption which is favourable to crack the intramolecular bond of the adsorbate molecule. This is an indication of chemisorption which contrasts the experimentally found physisorption for the dye molecules. From the high values of $E_{\text {bind }}$ obtained for the three dye molecules, only a probable chemisorption is expected which affirms the observed electron acceptance and backdonation of electrons at the same site. The very high binding energy of IB could be attributed to its $\mathrm{O}_{2}$ molecules 


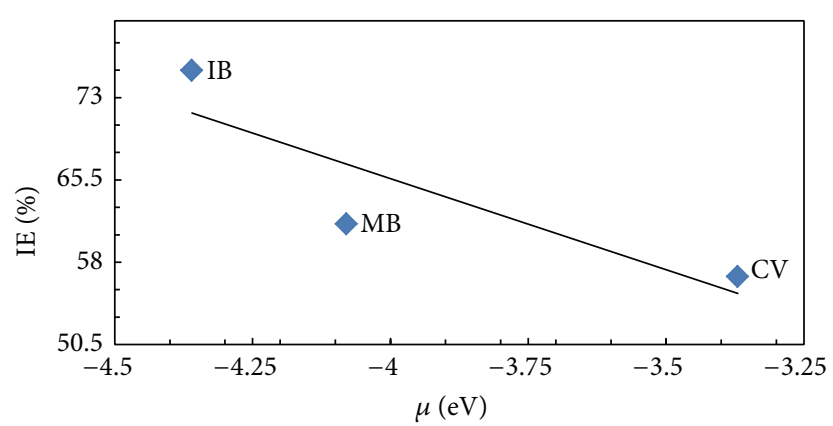

FIGURE 5: Correlation of chemical potential with percent inhibition efficiency of dye molecules.
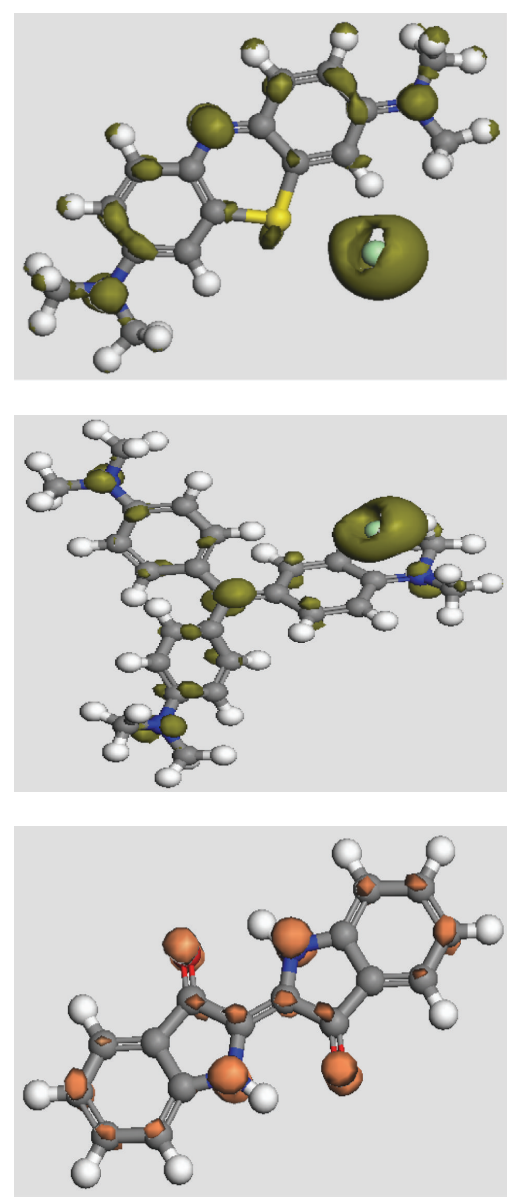

(a)

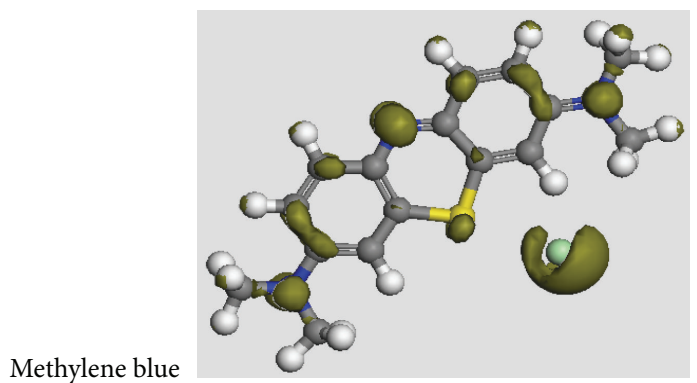

Crystal violet
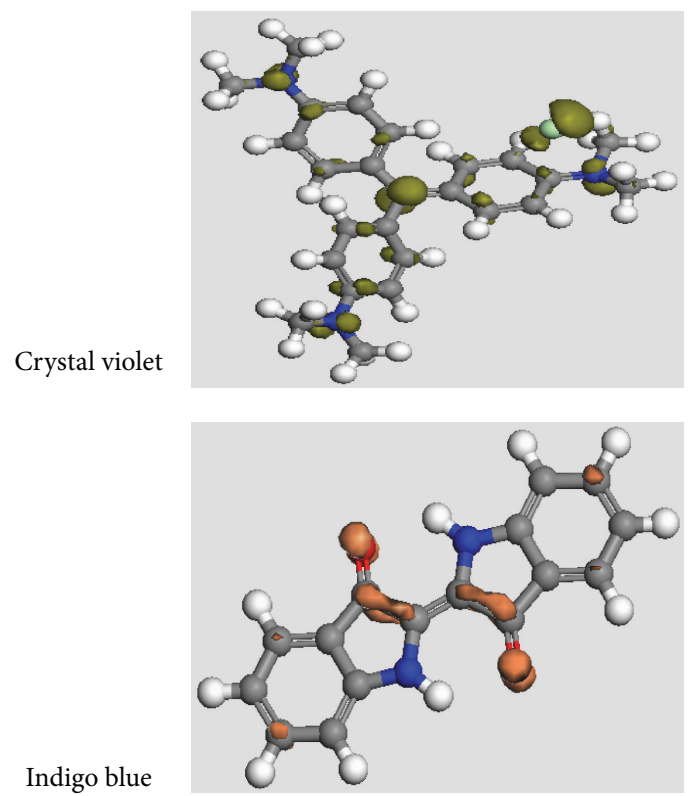

(b)

FIgURE 6: The Fukui indices density distributions of the three dyes: $f^{-}(\mathrm{a}) ; f^{+}(\mathrm{b})$.

which dissociate on adsorption. It can also be seen from Figure 7 that there is a linear correlation between the binding energy and inhibition efficiency indicating that the higher the binding energy, the higher the inhibition efficiency. Table 3 shows the values obtained for binding energy, interaction energy, and total energy. It can be seen that the trend of $E_{\text {Bind }}$ supports experimental results for the three dye molecules.

The high inhibition efficiency of IB could be attributed to a number of lone pair electrons on $\mathrm{O}$ atoms as well as the $\mathrm{N}$ atoms providing electrons to the unfilled $3 \mathrm{~d}$ orbitals of iron surface thereby forming a protective layer. Such protective film may act as a steric barrier that hinders the reactive ions/species from the aggressive environment from coming into contact with the metal surface, thus slowing down corrosion process. To determine the global minimum, various different low-energy minima were sampled. Figures $8(a)-8(c)$ show snapshots of the side view and top view (inset) of the lowest energy adsorption configurations for 


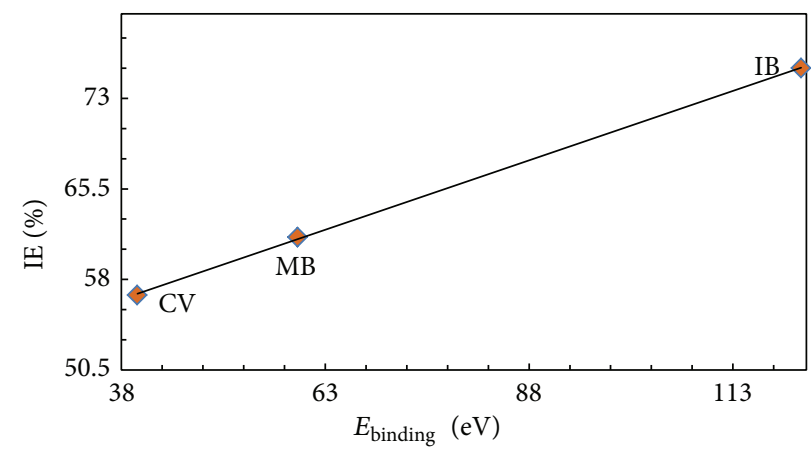

FiguRE 7: Correlation of binding energy with percent inhibition efficiency of dye molecules.

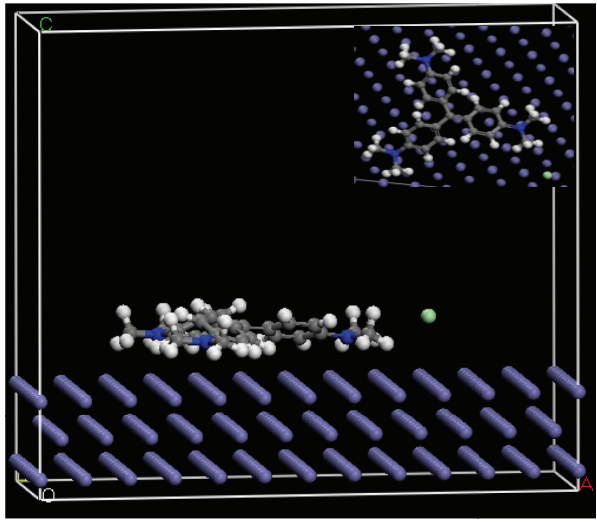

$\mathrm{CV}$

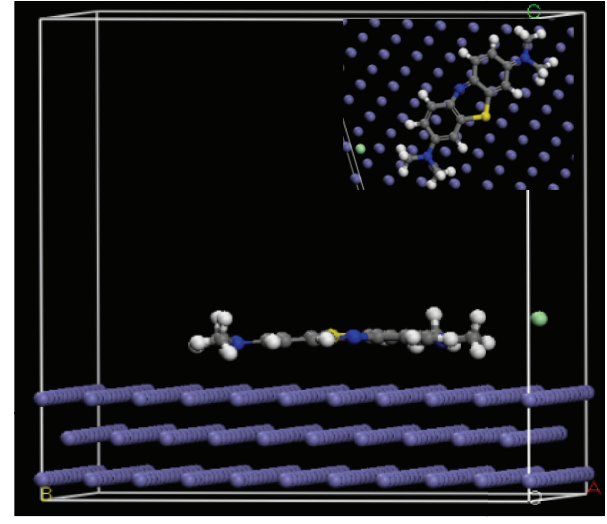

$\mathrm{MB}$

(b)

(a)

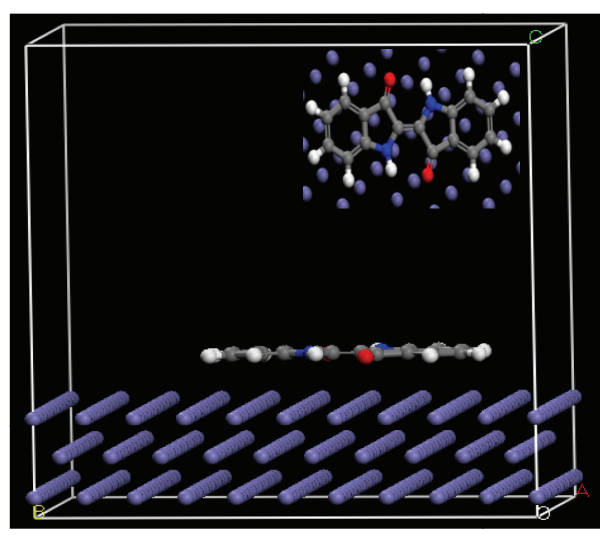

IB

(c)

FIGURE 8: Representative snapshots of (a) CV; (b) MB; and (c) IB adsorbed on Fe(110). Inset images show the on-top views, emphasizing the molecular backbone aligning with vacant sites on the fcc lattice atop the metal surface.

single inhibitor molecules studied on the $\mathrm{Fe}(110)$ surface from our simulations, respectively. Close inspection of the on-top view of adsorbed single molecule on $\mathrm{Fe}(110)$ reveals a very clear fashion in the adsorption configuration of all the molecules wherein polarizable atoms $(\mathrm{N}, \mathrm{O}, \mathrm{S})$ in the molecular backbone align with vacant sites on the fcc lattice atop the metal surface and virtually avoid contact with the $\mathrm{Fe}$ atoms on the surface plane.

\section{Conclusion}

In this study, the three dye molecules were the donators of electrons, and the iron surface was the acceptor. The compounds were adsorbed to the metal surface and hence formed inhibitive adsorption layer against the corrosive media. The inhibition efficiency is in order of $\mathrm{IB}>\mathrm{MB}>\mathrm{CV}$ which substantiates the experimental results. The research by quantum 
chemistry revealed that the reactive sites of dye molecules formed coordinate and back-donating bonds with atoms on metal surface. Further comparison revealed that the zones for electron donation were the same as the zones for accepting electrons which could indicate a probable chemisorption. IB had the highest inhibition efficiency because it had the greatest ability of offering electrons, and CV had the lowest inhibition efficiency. A linear correlation was observed between inhibition efficiencies and the inhibitor chemical potential as well as the extent of charge transfer to the metals. Furthermore, the distribution of electronic density shows that the dye molecules had many negatively charged active centers with exception of IB. The electron density was found to be positively correlated with its linear structure, which could be the effect for increase in inhibition efficiency. The zones containing $\mathrm{N}, \mathrm{O}$, and $\mathrm{S}$ atoms are the most possible sites for adsorption of the metal iron surface. This study suggests that theoretical method might be an effective approach to assess the inhibition performance of new inhibitors.

\section{References}

[1] A. D. Becke, "Density-functional exchange-energy approximation with correct asymptotic behavior," Physical Review A, vol. 38, pp. 3098-3100, 1988.

[2] I. B. Obot and N. O. Obi-Egbedi, "Theoretical study of benzimidazole and its derivatives and their potential activity as corrosion inhibitors," Corrosion Science, vol. 52, no. 2, pp. 657660, 2010.

[3] M. Şahin, G. Gece, F. Karc1, and S. Bilgic, "Experimental and theoretical study of the effect of some heterocyclic compounds on the corrosion of low carbon steel in $3.5 \% \mathrm{NaCl}$ medium," Journal of Applied Electrochemistry, vol. 38, no. 6, pp. 809-815, 2008.

[4] D. X. Wang and H. M. Xiao, "Quantum chemical calculation on chemical adsorption energy of imidazolines and Fe atom," Journal of Molecular Science, vol. 16, pp. 102-105, 2000.

[5] E. E. Oguzie, C. K. Enenebeaku, C. O. Akalezi, S. C. Okoro, A. A. Ayuk, and E. N. Ejike, "Adsorption and corrosion-inhibiting effect of Dacryodis edulis extract on low-carbon-steel corrosion in acidic media," Journal of Colloid and Interface Science, vol. 349, no. 1, pp. 283-292, 2010.

[6] E. Jamalizadeh, S. M. A. Hosseini, and A. H. Jafari, "Quantum chemical studies on corrosion inhibition of some lactones on mild steel in acid media," Corrosion Science, vol. 51, no. 6, pp. 1428-1435, 2009.

[7] M. Karelson, V. S. Lobanov, and A. R. Katritzky, "Quantumchemical descriptors in QSAR/QSPR studies," Chemical Reviews, vol. 96, no. 3, pp. 1027-1043, 1996.

[8] M. A. Amin, K. F. Khaled, Q. Mohsen, and H. A. Arida, "A study of the inhibition of iron corrosion in $\mathrm{HCl}$ solutions by some amino acids," Corrosion Science, vol. 52, pp. 1684-1695, 2010.

[9] G. Gece, S. Bilgic, and O. Turksen, "Quantum chemical studies of some amino acids on the corrosion of cobalt in sulfuric acid solution," Materials and Corrosion, vol. 61, no. 2, pp. 141-146, 2010.

[10] C. Gruber and V. Buss, "Quantum-mechanically calculated properties for the development of quantitative structure-activity relationships (QSAR'S). pKA-values of phenols and aromatic and aliphatic carboxylic acids," Chemosphere, vol. 19, no. 10-11, pp. 1595-1609, 1989.
[11] J. Fu, S. Li, Y. Wang, L. Cao, and L. Lu, "Computational and electrochemical studies of some amino acid compounds as corrosion inhibitors for mild steel in hydrochloric acid solution," Journal of Materials Science, vol. 45, pp. 6255-6265, 2010.

[12] J. Fang and J. Li, "Quantum chemistry study on the relationship between molecular structure and corrosion inhibition efficiency of amides," Journal of Molecular Structure: THEOCHEM, vol. 593, pp. 179-185, 2002.

[13] R. M. Issa, M. K. Awad, and F. M. Atlam, "Quantum chemical studies on the inhibition of corrosion of copper surface by substituted uracils," Applied Surface Science, vol. 255, no. 5, part 1, pp. 2433-2441, 2008.

[14] A. Yurt, G. Bereket, and C. Ogretir, "Quantum chemical studies on inhibition effect of amino acids and hydroxy carboxylic acids on pitting corrosion of aluminium alloy 7075 in $\mathrm{NaCl}$ solution," Journal of Molecular Structure: THEOCHEM, vol. 725, no. 1-3, pp. 215-221, 2005.

[15] G. Gece, "The use of quantum chemical methods in corrosion inhibitor studies," Corrosion Science, vol. 50, no. 11, pp. 29812992, 2008.

[16] G. Zhang and C. B. Musgrave, "Comparison of DFT methods for molecular orbital eigenvalue calculations," Journal of Physical Chemistry A, vol. 111, no. 8, pp. 1554-1561, 2007.

[17] G. Bereket, E. Hur, and C. Ogretir, "Quantum chemical studies on some imidazole derivatives as corrosion inhibitors for iron in acidic medium," Journal of Molecular Structure: THEOCHEM, vol. 578, pp. 79-88, 2002.

[18] J. Vosta and J. Eliasek, "Study on corrosion inhibition from aspect of quantum chemistry," Corrosion Science, vol. 11, pp. 223-229, 1971.

[19] E. E. Oguzie, Y. Li, S. G. Wang, and F. Wanga, "Understanding corrosion inhibition mechanisms-experimental and theoretical approach," RSC Advances, vol. 1, pp. 866-873, 2011.

[20] S. Xia, M. Qiu, L. Yu, F. Liu, and H. Zhao, "Molecular dynamics and density functional theory study on relationship between structure of imidazoline derivatives and inhibition performance," Corrosion Science, vol. 50, no. 7, pp. 2021-2029, 2008.

[21] F. Kandemirli and S. Sagdinc, "Theoretical study of corrosion inhibition of amides and thiosemicarbazones," Corrosion Science, vol. 49, no. 5, pp. 2118-2130, 2007.

[22] C. D. Taylor, R. G. Kelly, and M. Neurock, "A first-principles analysis of the chemisorption of hydroxide on copper under electrochemical conditions: a probe of the electronic interactions that control chemisorption at the electrochemical interface," Journal of Electroanalytical Chemistry, vol. 607, no. 1-2, pp. 167-174, 2007.

[23] D. Wanga, S. Lia, Y. Yinga, M. Wanga, H. Xiaob, and Z. Che, "Theoretical and experimental studies of structure and inhibition efficiency of imidazoline derivatives," Corrosion Science, vol. 41, no. 10, pp. 1911-1919, 1999.

[24] J. Bartley, N. Huynh, S. E. Bottle, H. Flitt, T. Notoya, and D. P. Schweinsberg, "Computer simulation of the corrosion inhibition of copper in acidic solution by alkyl esters of 5-carboxybenzotriazole," Corrosion Science, vol. 45, no. 1, pp. 81-96, 2003.

[25] E. E. Oguzie, S. G. Wang, Y. Li, and F. H. Wang, "Influence of iron microstructure on corrosion inhibitor performance in acidic media," Journal of Physical Chemistry C, vol. 113, no. 19, pp. 8420-8429, 2009.

[26] L. M. Rodríguez-Valdez, A. Martínez-Villafañe, and D. Glossman-Mitnik, "Computational simulation of the molecular structure and properties of heterocyclic organic compounds 
with possible corrosion inhibition properties," Journal of Molecular Structure: THEOCHEM, vol. 713, no. 1-3, pp. 65-70, 2005.

[27] A. Lesar and I. Milošev, "Density functional study of the corrosion inhibition properties of 1,2,4-triazole and its amino derivatives," Chemical Physics Letters, vol. 483, no. 4-6, pp. 198-203, 2009.

[28] E. E. Oguzie, C. Unaegbu, C. N. Ogukwe, B. N. Okolue, and A. I. Onuchukwu, "Inhibition of mild steel corrosion in sulphuric acid using indigo dye and synergistic halide additives," Materials Chemistry and Physics, vol. 84, no. 2-3, pp. 363-368, 2004.

[29] E. E. Oguzie, "Corrosion inhibition of mild steel in hydrochloric acid solution by methylene blue dye," Materials Letters, vol. 59, no. 8-9, pp. 1076-1079, 2005.

[30] W. Yang and R. Parr, "Hardness, softness, and the fukui function in the electronic theory of metals and catalysis," Proceedings of the National Academy of Sciences of the United States of America, vol. 82, pp. 6723-6726, 1985.

[31] E. E. Oguzie, G. N. Onuoha, and A. I. Onuchukwu, "Inhibitory mechanism of mild steel corrosion in $2 \mathrm{M}$ sulphuric acid solution by methylene blue dye," Materials Chemistry and Physics, vol. 89, no. 2-3, pp. 305-311, 2005.

[32] E. E. Oguzie, V. O. Njoku, C. K. Enenebeaku, C. O. Akalezi, and C. Obi, "Effect of hexamethylpararosaniline chloride (crystal violet) on mild steel corrosion in acidic media," Corrosion Science, vol. 50, no. 12, pp. 3480-3486, 2008. 

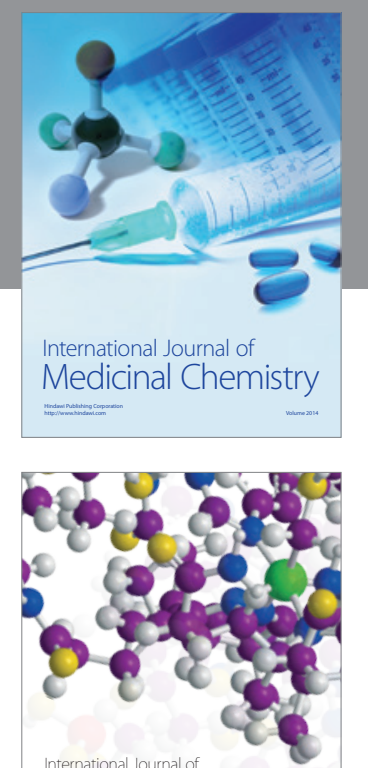

\section{Carbohydrate} Chemistry

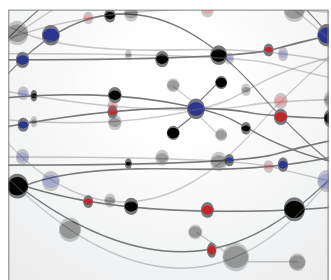

The Scientific World Journal
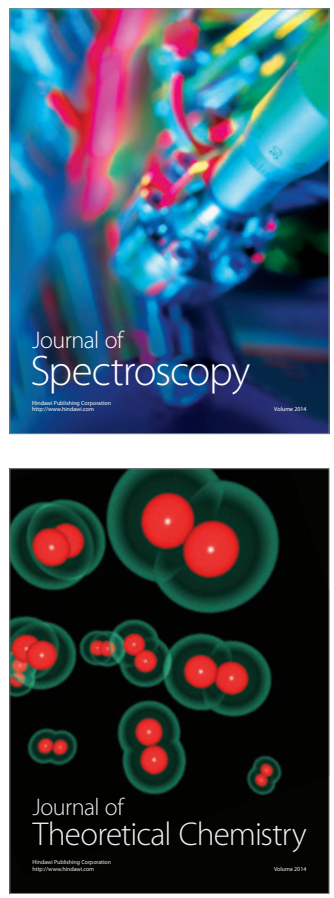
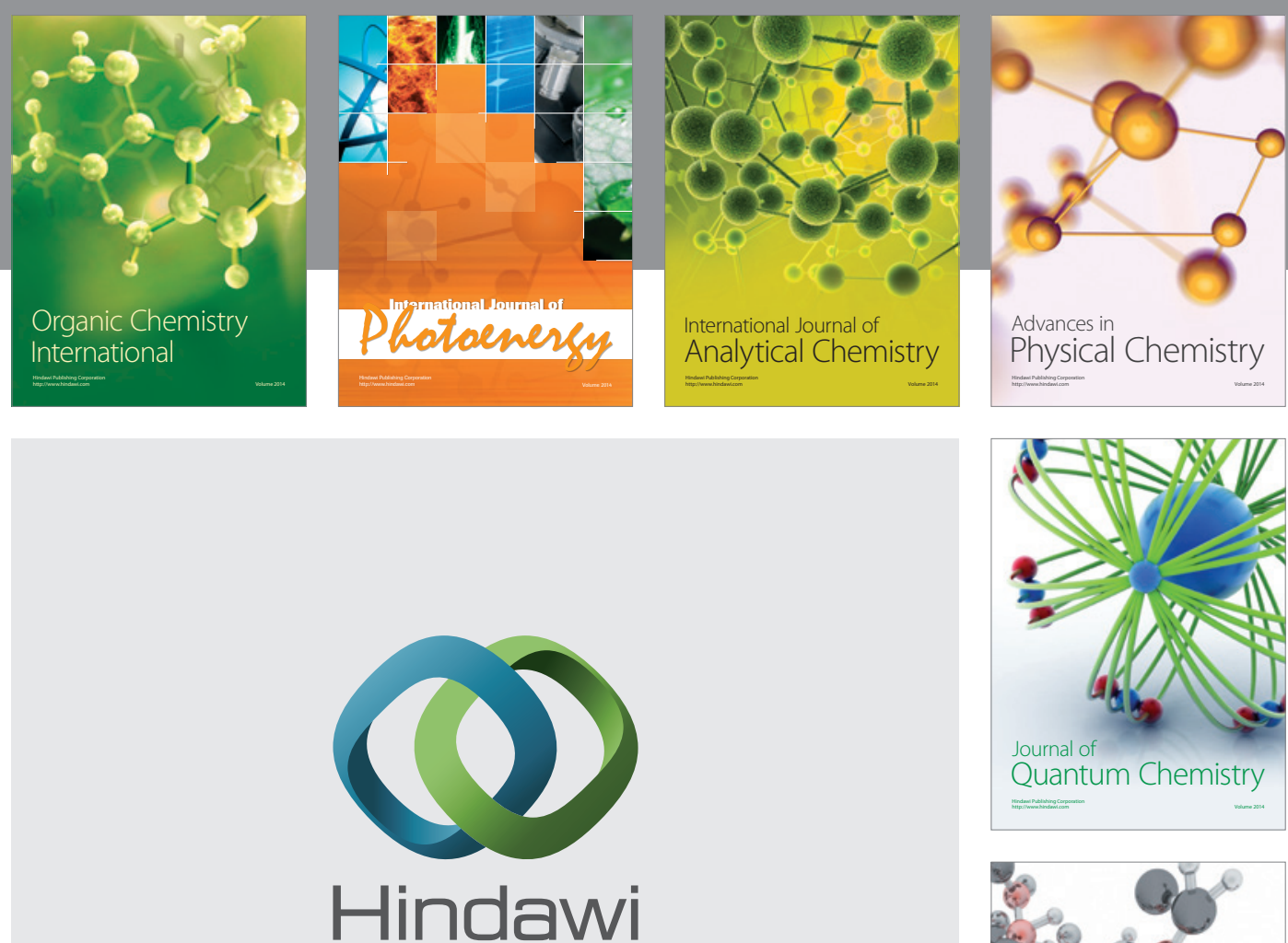

Submit your manuscripts at

http://www.hindawi.com

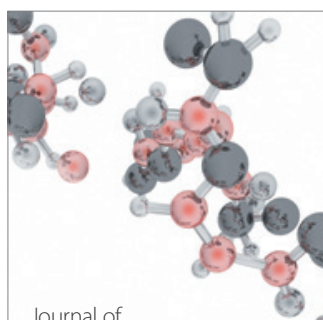

Analytical Methods

in Chemistry

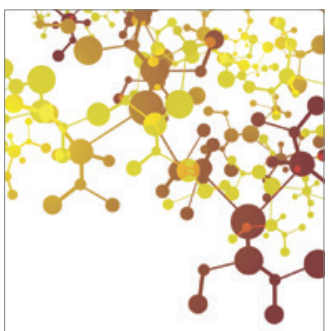

Journal of

Applied Chemistry

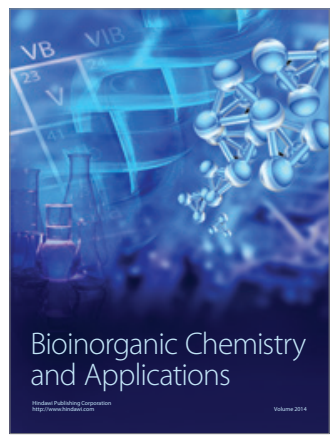

Inorganic Chemistry
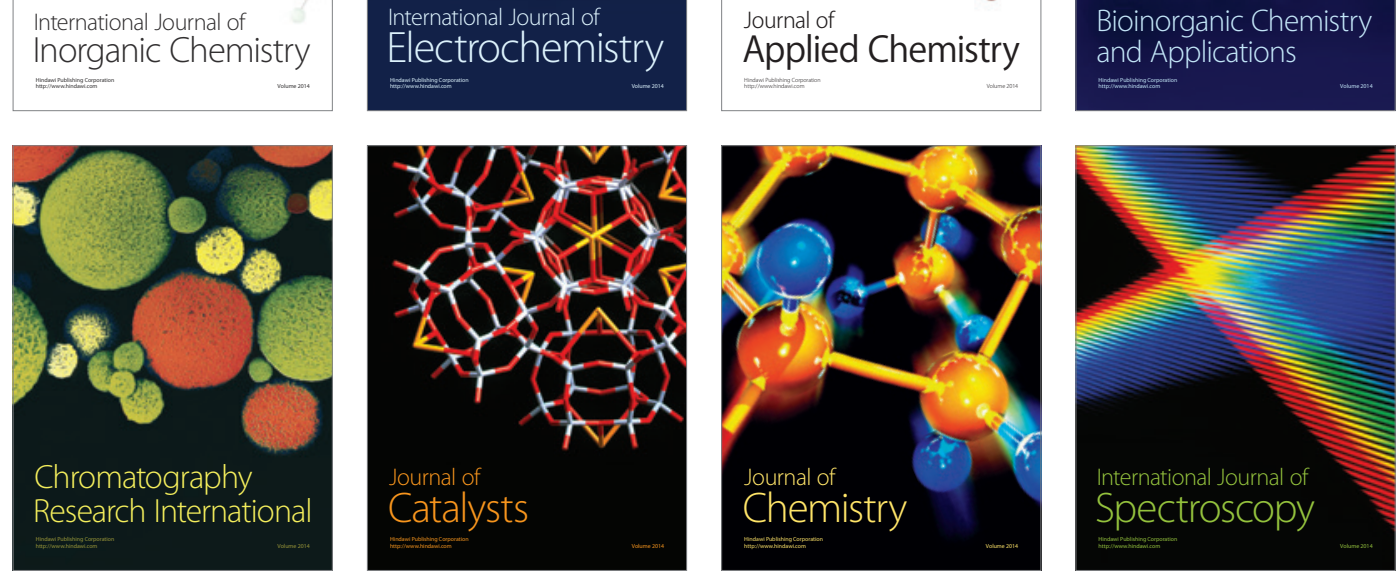